\title{
Las fuerzas políticas cordobesas entre el orden notabiliar y la ampliación de la democracia
}

\author{
Consideraciones en torno a los conceptos de derechas e izquierdas
}

\author{
Javier Moyano
}

Universidad Nacional de Córdoba

\section{Introducción}

En este ensayo nos proponemos problematizar la pertinencia de clasificar como conservadoras o progresistas a diferentes fuerzas políticas cordobesas con protagonismo entre fines del siglo XIX y las primeras décadas del $\mathrm{xx}$, en especial a partir del posicionamiento ante conflictos que en diferentes momentos dividieron a la sociedad local en torno al tipo de régimen político y a las relaciones entre Estado e Iglesia. El punto de inicio de nuestro análisis coincide con las primeras impugnaciones de peso, desde 1890, al régimen político notabiliar, o bien oligárquico, inaugurado diez años antes con el acceso de Julio A. Roca a la presidencia argentina. El cierre se ubica en el golpe de Estado de 1930, que clausuró momentáneamente la experiencia de democracia más abierta y competitiva resultante de la reforma electoral de 1912.

Los actores seleccionados son, por un lado, las fuerzas políticas que, con diversa organicidad, antes y después de 1912 reunieron a los grupos gobernantes del régimen oligárquico, como el Partido Autonomista Nacional (PAN), al frente del ejecutivo cordobés hasta 1909, el Partido Demócrata, fundado en 1913, y un conjunto de agrupaciones de existencia más efímera. Por otro lado, corrientes con actuación, permanente o eventual, en el radica- lismo. En el interior de estas fuerzas políticas visualizaremos la actuación de algunas camarillas, como los juaristas, alineados en la década de 1880 con el presidente Miguel Juárez Celman, y con protagonismo tras su renuncia en 1890; los roquistas, enrolados con Julio A. Roca, sector predominante en Córdoba entre 1890 y la intervención federal de 1909 , y un conjunto de grupos clericales con niveles de organicidad más inestables. Cabe señalar, además, que mientras los dos primeros grupos solo participaron en partidos rivales del radicalismo, algunas camarillas clericales fluctuaron entre el apoyo al radicalismo y a sus adversarios.

\section{Conservadurismos, progresismos, derechas e izquierdas}

La pregunta en torno al conservadurismo y al progresismo pretende contribuir al abordaje del interrogante sobre la pertinencia de los conceptos de derechas e izquierdas para caracterizar a las fuerzas políticas cordobesas durante el período en cuestión. Compartimos aquí algunas preocupaciones expuestas en otras contribuciones de este dossier, como las formuladas por Ana Teresa Martinez respecto al uso de los conceptos de izquierdas y derechas como categorías nativas o categorías 
analíticas, y a sus límites en tanto términos exhaustivos y exclusivos; ${ }^{1}$ o bien las planteadas por Roberto Pittaluga acerca de la distinción entre las dimensiones posicionales o identitarias de ambos conceptos. ${ }^{2}$

Si pensamos en izquierdas y derechas como categorías nativas, encontramos que en Córdoba las referencias a ambas como conceptos clasificadores, para construir la identidad propia o para definir al adversario, estuvieron ausentes en el discurso público de los principales actores hasta los comicios presidenciales de 1928, cuando los rivales del yrigoyenismo confluyeron en la denominada Confederación de Derechas. Ahora bien, si asumimos los conceptos de izquierdas y derechas como categorías analíticas, es posible aproximarnos al problema a partir de la toma de posiciones conservadoras o progresistas ante asuntos que antagonizaban a las fuerzas políticas. Esto conduce a la distinción, planteada por Pittaluga, sobre el uso de los conceptos de izquierdas y derechas en sus dimensiones relacionales o identitarias. ${ }^{3}$ En ese sentido, si utilizamos los conceptos de izquierdas y derechas como categorías analíticas en sus dimensiones relacionales, es posible abordar a las fuerzas políticas cordobesas en función de los asuntos sobre los cuales antagonizaban, aunque, como argumentaremos luego, este registro no da cuenta de la totalidad de los posicionamientos de los actores locales. Si, en cambio, nos detenemos en las dimensiones identitarias, en el caso cordobés el antagonismo entre "conservadurismo" y "progresismo" se presenta como más operativo que la oposición entre izquierdas y derechas, si bien el uso polisémico, en el lenguaje de la época, del concepto de conservadurismo, sumado a las metamorfosis expe-

\footnotetext{
${ }^{1}$ Ana Teresa Martinez, "Clasificar lo inclasificable: izquierda y derecha como categorías nativas".

${ }^{2}$ Roberto Pittaluga, "Notas para una historia de la izquierda".

${ }^{3}$ Ibid.
}

rimentadas en la historia del concepto, puede plantearnos algunas dificultades. Asimismo, en términos exclusivamente analíticos, es posible efectuar deslizamientos entre conservadurismo y derechas, y entre progresismo e izquierdas.

Sin desconocer las dificultades, advertidas por Ana Teresa Martinez, que supone el uso con pretensiones científicas de las categorías en cuestión, ${ }^{4}$ si priorizamos el uso analítico de los conceptos de izquierdas y derechas en sus dimensiones relacionales estimamos posible aproximarnos a la problemática planteada a partir del antagonismo entre conservadurismo y progresismo, entendiendo los conservadurismos, como lo hace José Luis Romero, como aquellas corrientes que buscaban preservar estructuras establecidas en oposición a aquellas fuerzas -que denominaremos progresistas- promotoras de su transformación. ${ }^{5}$ Sin negar la existencia de vínculos entre liberalismo y derechas, en especial con respecto a la cuestión de la democracia, vínculos problematizados en la contribución a este dossier de Leandro Losada, ${ }^{6}$ si analizamos a las izquier-

\footnotetext{
${ }^{4}$ Martinez, "Clasificar".

${ }^{5}$ José Luis Romero, "Prólogo", en J. L. Romero y L. A. Romero (comp., notas y cronología), Pensamiento conservador (1815-1898), Caracas, Biblioteca Ayacucho, 1978, pp. IX-XXXviII. Cabe advertir que el estudio de Romero considera una etapa anterior a la abordada en este ensayo. En ese sentido, como ha señalado Oscar Terán, las transformaciones en la sociedad argentina a fines del siglo XIX y principios del XX contribuyeron a modificar el significado del conservadurismo -y por ende del progresismo- en dos direcciones: por un lado en la tendencia a la asociación, con fines autolegitimadores, entre los conceptos de "intereses conservadores" y "progreso material"; y por otro, en el peso de la preocupación por los efectos no deseados de una modernización promovida por las mismas élites que se asumían como conservadoras, en especial en lo relativo a los conflictos obreros y a la presencia de amplios contingentes migratorios. Oscar Terán, Vida intelectual en el Buenos Aires Fin de siglo (1880-1910). Derivas de la "cultura científica”, Buenos Aires, FCE, 2000, pp. 16-25.

${ }^{6}$ Leandro Losada, "Liberalismo y derechas en Argentina, 1912-1943. Apuestas interpretativas, posibilidades y límites".
} 
das y derechas en su dimensión relacional, también es posible ubicar al liberalismo a la izquierda del clericalismo cuando el antagonismo en torno a las relaciones entre Iglesia y Estado ocupó el centro de la escena.

\section{Clivajes y procedencia social como criterios clasificadores}

Abordaremos aquí la toma de posición ante dos clivajes que dividieron a la sociedad cordobesa en diversos momentos: el antagonismo en torno al régimen político, que adquirió centralidad hacia 1890, y luego nuevamente durante la primera década $-\mathrm{y}$ parte de la segunda- del siglo xx; y la disputa entre laicistas y clericales que también dividía a la dirigencia en la coyuntura revolucionaria de 1890, y nuevamente lo hizo en 1918. Con un énfasis menor, también consideraremos la procedencia social de los núcleos dirigentes de las fuerzas políticas sobre la base del argumento de Edward Gibson, quien privilegia esa variable a la hora de clasificar como conservador a un partido. ${ }^{7}$

Con respecto a los conflictos en torno al tipo de régimen político, adscribimos a la identificación entre conservadurismo y prioridad asignada al orden por encima de la participación, destacada por Natalio Botana y Ezequiel Gallo. ${ }^{8}$ En este sentido, el radicalismo, fundado en 1891, aglutinó a los sectores que habían impugnado el régimen oligárquico desde la revolución de 1890 hasta la sanción de la ley Sáenz Peña. En tanto, los dirigentes que antes de 1912 habían actuado dentro de

\footnotetext{
${ }^{7}$ Edward L. Gibson, Class and Conservative Parties. Argentina in Comparative Perspective, Baltimore y Londres, The Johns Hopkins University Press, 1996, p. 12. ${ }^{8}$ Natalio Botana y Ezequiel Gallo, De la república posible a la república verdadera (1880-1910), Buenos Aires, Biblioteca del Pensamiento Argentino, Ariel,1997, pp. 30-34.
}

las fronteras del régimen oligárquico participaron en el PAN -predominante en Córdoba hasta la intervención federal de 1909- y en agrupamientos eventualmente aliados de esa fuerza política, y después de 1909 en sucesivos conglomerados gobernantes. Luego de 1912, la mayoría de estos dirigentes confluyeron en una alianza, la Concentración Popular y, desde fines de 1913, convergieron en el Partido Demócrata, gobernante en la provincia durante la mayor parte del período comprendido entre 1912 y 1930. Aunque correcta en líneas generales, la oposición en torno al tipo de régimen presenta algunas complejidades. Por un lado, desde los grupos gobernantes del orden oligárquico surgieron los reformadores que en 1912 modificaron la legislación electoral, y entre ellos fue decisiva la actuación de camarillas cordobesas de antigua pertenencia al juarismo que, paradójicamente, en la década de 1880 había sido el segmento más renuente a admitir la participación ciudadana en asuntos públicos. ${ }^{9}$ Por otro lado, el radicalismo incorporó, en diferentes momentos, camarillas que habían participado en alianzas oficialistas antes de 1912.

$\mathrm{Si}$ nos detenemos en los conflictos en torno a las relaciones entre Estado e Iglesia, que habían enfrentado a la dirigencia en la década de 1880, y que en los años previos y posteriores a la reforma universitaria de 1918 recuperaron centralidad en Córdoba, el primer señalamiento es que el juarismo, el grupo más autoritario en lo atinente a las discusiones en torno al régimen político en los ochenta, había sido en esa etapa el segmento más decididamente laicista entre los sectores gobernantes. El roquismo, en cambio, a partir de 1890 consolidó su predominio en Córdoba, que se prolongó hasta 1909, sobre la base de alternativas alianzas con camarillas juaristas o con grupos clericales, para lo cual

\footnotetext{
${ }^{9}$ Botana y Gallo, De la república posible, p. 36.
} 
desterró de su agenda las iniciativas programáticas que afectaran esa estrategia. Diversas camarillas clericales, en tanto, participaron recurrentemente en alianzas con el roquismo entre 1890 y mediados de la primera década del siglo $\mathrm{xx}$, y luego tendieron a confluir con los juaristas -rivales ideológicos en lo atinente a las relaciones entre Estado e Iglesia- en la impugnación al roquismo y en el patrocinio de la reforma electoral. Aunque el roquismo había sido más moderado que el juarismo en sus posiciones laicistas, los grupos que habían polarizado en torno a esas cuestiones se unían luego como parte de una estrategia para enfrentar a un rival más poderoso. El radicalismo, en tanto, se había nutrido desde su nacimiento con recurrentes incorporaciones de camarillas clericales, aunque la permanencia de las mismas en ese partido no era, por lo general, demasiado prolongada.

Ante los sucesos de la Reforma Universitaria, cuando el antagonismo entre laicistas y clericales recuperó el centro de la escena local, había radicales y demócratas tanto entre los reformistas como entre sus adversarios. Si bien fue decisivo el apoyo del gobierno nacional, presidido por Yrigoyen, a las demandas reformistas, el oficialismo provincial, también en manos del radicalismo desde principios de 1916, era clerical, e incluso algunas iniciativas de su gestión, en materia educativa y en la comisión de diversos actos de censura, habían contribuido a la escalada del antagonismo entre católicos y liberales. Poco después de conquistar el gobierno provincial en 1916, el radicalismo se dividió, en especial por la disconformidad de sectores internos desfavorecidos en la distribución de beneficios y enfrentados a los clericales que controlaban el ejecutivo. ${ }^{10}$ El mismo gobierno na-

${ }^{10}$ Gardenia Vidal, Radicalismo de Córdoba. 1912-1930. Los grupos internos: alianzas, conflictos, ideas, actores, cional que en 1918 apoyaría las demandas de los reformistas en contra de sus rivales católicos, muchos de ellos radicales, poco antes tomaba partido por los clericales ante la división del radicalismo local, decisión que se explicaba por la inconveniencia, para el yrigoyenismo, de enemistarse con uno de los pocos gobiernos provinciales en manos radicales en ese momento. Muchos de esos radicales clericales recalarían en el alvearismo a fines de la década de 1920 y participarían en la Confederación de Derechas entre 1927 y 1928. Sin embargo, en 1918 la principal voz contraria a los reformistas en el Parlamento nacional fue la del diputado clerical Enrique Martínez, ${ }^{11}$ quien posteriormente, entre 1928 y 1930, sería el vicepresidente de Yrigoyen.

Con respecto a la procedencia social de sus núcleos dirigentes, en las agrupaciones y conglomerados que reunieron, antes y después de 1912, a los grupos gobernantes del régimen oligárquico, esa dirigencia tuvo un perfil predominantemente notabiliar, pues se integraba con miembros de familias vinculadas con el poder económico y/o con la administración de justicia y la docencia universitaria, en una etapa en la cual el reclutamiento del personal judicial y académico distaba de ser abierto. Un conjunto de relaciones vinculaba, además, a los miembros de tales familias entre sí. En el radicalismo, en cambio, la pertenencia social de los núcleos dirigentes era más diversa pues, aunque también los integraron personas pertenecientes a ese patriciado, muchos dirigentes de clase media ocuparon importantes espacios de poder en su interior.

Córdoba, Universidad Nacional de Córdoba, 1995, pp. 45-50.

${ }^{11}$ Liliana Aguiar de Zapiola, "El radicalismo y la reforma ¿Orígenes míticos de las clases medias en Córdoba?", Anuario del Centro de Estudios Avanzados, Universidad Nacional de Córdoba, 1994, pp. 123-250. 


\section{Los límites de la clasificación}

En lo relativo a la defensa de estructuras preexistentes o al patrocinio de su transformación, podemos clasificar como conservadores a quienes asumían posiciones clericales, apoyaban el régimen oligárquico anterior a 1912 y representaban intereses de las élites sociales; y como progresistas a quienes adherían al laicismo, promovían la ampliación de la democracia y expresaban intereses de las clases medias. No había, sin embargo, un vínculo lineal entre la toma de partido ante este conjunto de antagonismos, pues, por ejemplo, un dirigente laicista podía ser, al mismo tiempo, opositor a la ampliación democrática. Tampoco se verifica una correspondencia necesaria entre la adscripción partidaria y el posicionamiento ante la totalidad de esos antagonismos.

Esa ausencia de linealidad obedece a diversos factores. En primer lugar, al cambiante posicionamiento de dirigentes y camarillas ante algunos de estos antagonismos. Juaristas promoviendo la reforma del régimen político, o clericales alineados, alternativamente, en el radicalismo o en las agrupaciones rivales de ese partido, son algunos ejemplos al respecto. En segundo lugar, la mediana heterogeneidad, en lo relativo a la procedencia social y a la toma de posición ante algunos de los conflictos señalados, por parte de la dirigencia que revistaba en diversas agrupaciones. Cabe citar, por ejemplo, la integración en los núcleos dirigentes del radicalismo de miembros de las élites locales; o bien la coexistencia de clericales y laicistas en casi todas las fuerzas políticas. En tercer lugar, la recurrente emergencia, en momentos de polarización ideológica, de figuras mediadoras, que fundaban su posición de poder en la capacidad de establecer alternativas alianzas con alguno de los grupos antagónicos. El caso del roquismo tras la revolución de 1890 es un ejemplo de ello. En cuarto lugar, las mediaciones que establecía la competencia por el poder respecto al posicionamiento frente a diversos conflictos. El alternativo apoyo del yrigoyenismo a los radicales clericales primero, y a los estudiantes reformistas luego, se explica por cuestiones de este tipo. Algo similar puede afirmarse respecto a la convergencia, al promediar la primera década del siglo $\mathrm{xx}$, entre juaristas y clericales para enfrentar al roquismo.

En función de los dilemas planteados, es posible establecer un diálogo entre el estudio del caso cordobés y reflexiones de autores que han analizado problemáticas cercanas en otra escala. En primer lugar, cabe retomar los aportes de José Luis Romero, en especial en torno a dos cuestiones: la posibilidad de ser conservador, calificativo que no necesariamente implicaba la adhesión a un conjunto homogéneo de postulados, respecto de alguna instancia de la estructura y no serlo respecto de otra. Por otro lado, con excepción de los segmentos más intransigentes, el pragmatismo, la respuesta adaptativa según el tipo de desafíos a afrontar y la disposición a transigir con el cambio por parte de los conservadores, y a negociar con las inercias por parte de muchos reformadores. ${ }^{12}$ En segundo lugar, las reflexiones de Ezequiel Gallo respecto al carácter sui generis del conservadurismo argentino, en tanto la incidencia de la tradición conservadora en la construcción del Estado había sido más débil que la ejercida por el liberalismo. ${ }^{13}$ En tercer lugar, el señalamiento de Botana y Gallo en lo relativo a definir como conservadores a quienes asignaban prioridad al orden, y en función de ello defendían el control autoritario del gobierno, independientemente de la programática que promovieran. ${ }^{14}$ En cuarto lugar, el análisis de Edward Gibson, quien ubica el origen social del núcleo dirigente de un partido

\footnotetext{
${ }^{12}$ Romero, "Prólogo", pp. IX-XXXVIII.

${ }^{13}$ Ezequiel Gallo, "Entrevista", en Marcelo Montserrat, La experiencia conservadora, Buenos Aires, Editorial Sudamericana, Fundación Argentina, 1992, pp. 82-94.

${ }^{14}$ Botana y Gallo, De la república posible, p. 36.
} 
como una variable privilegiada a la hora de clasificarlo como conservador. ${ }^{15}$ En quinto lugar, la advertencia de Devoto y Roldán respecto a que las "derechas" incluyen a distintos grupos, y engloban componentes ideológicos heterogéneos y contradictorios. ${ }^{16}$ En sexto lugar, el aserto de Olga Echeverría respecto a que las derechas, lejos de ser monolíticas, son "colectivos diversos", en permanente construcción y reconstrucción de su identidad. ${ }^{17}$

\section{A modo de cierre}

Consideramos que la defensa de las estructuras establecidas, la prioridad asignada al orden desde el control autoritario del gobierno o la pertenencia a las élites sociales por parte de su núcleo dirigente constituyen elementos pertinentes para calificar a un grupo como conservador. Sin embargo, la visualización de diversos límites obliga a tomar precauciones y a advertir sobre matices que se presentan de modo recurrente si pretendemos caracterizar como conservadoras o progresistas a las fuerzas políticas cordobesas de fines del siglo XIX y principios del $\mathrm{xx}$, y más aun si nuestra intención es clasificarlas como de izquierdas y derechas. Por un lado, la centralidad de un clivaje en un momento determinado no definía la totalidad de los posicionamientos de dirigentes y camarillas ante esos antagonismos. Por otro lado, aun cuando lo hiciera, tales antagonismos no siempre eran decisivos

\footnotetext{
${ }^{15}$ Gibson, Class and Conservative, p. 12.

${ }^{16}$ Fernando Devoto y Darío Roldán, "Los orígenes ideológicos de las derechas en Europa e Iberoamérica", Estudios Sociales, $\mathrm{n}^{\circ}$ 33, 2007, pp. 9-14.

${ }^{17}$ Olga Echeverría, "Los intelectuales de derecha frente a la nación y lo popular. Argentina, primeras décadas del siglo xx", Estudos Ibero-Americano, vol. 42, n 1, 2016 , pp. 12-33.
}

para definir pertenencias partidarias o el establecimiento y la ruptura de alianzas electorales. Se visualiza aquí la dificultad de cualquier pretensión de pensar a la izquierda y la derecha en sentido monolítico, y mucho menos si de esa manera se intenta clasificar a las principales agrupaciones partidarias.

Esta advertencia no invalida, sin embargo, el interrogante sobre la pertinencia de utilizar las oposiciones entre conservadurismo y progresismo, y entre derechas e izquierdas, para analizar la política durante el período en cuestión, pues diversos argumentos avalan esa pretensión si abordamos el problema en sus dimensiones relacionales. Por un lado, el radicalismo se posicionó a la izquierda de sus adversarios en uno de los antagonismos que en diferentes momentos ocupó el centro de la escena: la impugnación o defensa del régimen político -oligárquico o notabiliar antes de 1912; de democracia ampliada luego de esa fecha- antes y después de la sanción de la ley Sáenz Peña. Por otro lado, sin ser absolutas, es posible visualizar diferencias significativas en la procedencia social de la dirigencia.

$\mathrm{Si}$ nos concentramos en los clivajes que dividieron aguas en la sociedad cordobesa, podemos concluir que algunos de ellos tendían a definir, con marchas y contramarchas y nunca exentos de heterogeneidades, agrupamientos partidarios o alianzas políticas en torno a la defensa o la impugnación de estructuras establecidas. Otros, en cambio, se presentaban recortados de las pertenencias partidarias aunque podían influir, directa o indirectamente, sobre ellas. A modo de síntesis, podemos afirmar que, aunque los ejes conservadurismo versus progresismo e izquierdas versus derechas no explican en su totalidad las divisiones partidarias, sí contribuyen a hacerlo en lo relativo a algunos antagonismos significativos. 


\section{Bibliografía citada}

Aguiar de Zapiola, Liliana, "El radicalismo y la reforma ¿Orígenes míticos de las clases medias en Córdoba?”, Anuario Centro de Estudios Avanzados, Universidad Nacional de Córdoba, 1994.

Botana, Natalio y Ezequiel Gallo, De la república posible a la república verdadera (1880-1910), Buenos Aires, Biblioteca del Pensamiento Argentino, Ariel, 1997.

Devoto, Fernando y Darío Roldán, "Los orígenes ideológicos de las derechas en Europa e Iberoamérica", Estudios Sociales, $\mathrm{n}^{\circ} 33,2007, \mathrm{pp} .9-14$.

Echeverría, Olga, "Los intelectuales de derecha frente a la nación y lo popular. Argentina, primeras décadas del siglo xx", Estudos Ibero-Americano, v. 42, n 1, 2016, pp. 12-33.

Gallo, Ezequiel, "Entrevista", en Marcelo Montserrat, La experiencia conservadora, Buenos Aires, Editorial Sudamericana, Fundación Argentina 1992, pp. 82-94.

Gibson, Edward L., Class and Conservative Parties. Argentina in Comparative Perspective, Baltimore y Londres, The Johns Hopkins University Press, 1996.

\section{Resumen/Abstract}

Las fuerzas políticas cordobesas entre el orden notabiliar y la ampliación de la democracia. Consideraciones en torno a los conceptos de derechas e izquierdas

En este ensayo nos proponemos problematizar sobre la pertinencia de clasificar como conservadoras o progresistas a diferentes fuerzas políticas cordobesas con protagonismo entre fines del siglo XIX y las primeras décadas del $\mathrm{xx}$, en especial a partir del posicionamiento ante clivajes que en diferentes momentos dividieron la sociedad local en torno al tipo de régimen político y a las relaciones entre Estado e Iglesia. El punto de inicio de nuestro análisis coincide con las primeras impugnaciones de peso, desde 1890, al régimen oligárquico, inaugurado diez años antes con el acceso de Julio A. Roca a la presidencia argentina. El cierre se ubica en el golpe de Estado de 1930. Los actores seleccionados son, por un lado, las fuerzas políticas que, con diversa organicidad, antes y después de 1912 reunieron a los grupos gobernantes del régimen oligárquico. Por otro lado, corrientes con actuación, permanente o eventual, en el radicalismo.

Palabras clave: Conservadurismo - Progresismo Derechas - Izquierdas

Losada, Leandro, "Liberalismo y derechas en Argentina, 1912-1943. Apuestas interpretativas, posibilidades y límites", Prismas. Revista de Historia Intelectual, $\mathrm{n}^{\circ} 24$, 2020.

Martinez, Ana Teresa, "Clasificar lo inclasificable: izquierda y derecha como categorías nativas", Prismas. Revista de Historia Intelectual, ${ }^{\circ}$ 24, 2020.

Pittaluga, Roberto, "Notas para una historia de la izquierda", Prismas. Revista de Historia Intelectual, $\mathrm{n}^{\circ}$ 24, 2020.

Romero, José Luis, "Prólogo", en José Luis Romero y Luis Alberto Romero (compilación, notas y cronología), Pensamiento conservador (1815-1898), Caracas, Biblioteca Ayacucho, 1978, pp. IX-XXXVIII.

Terán, Oscar, Vida intelectual en el Buenos Aires Fin de siglo (1880-1910). Derivas de la "cultura científica", Buenos Aires, FCE, 2000.

Vidal, Gardenia, Radicalismo de Córdoba. 1912-1930. Los grupos internos: alianzas, conflictos, ideas, actores, Córdoba, Universidad Nacional de Córdoba, 1995.

Córdoba's political forces between the order of the notables and the expansion of democracy. Considerations on the concepts of left and right In this essay we propose to problematize the relevance of classifying different Cordovan political forces as conservative or progressive, with a leading role between the late nineteenth century and the first decades of the twentieth, especially from the position of cleavages that divided the local society -in around the type of political regime and the relations between State and Church-at different times. The starting point of our analysis coincides with the first major challenges, since 1890 , to the oligarchic regime, inaugurated ten years earlier with the accession of Julio A. Roca to the Argentine presidency. The closure is located in the coup d'état of 1930. The selected actors are, on the one hand, the political forces that, with different organicity, before and after 1912 brought together the ruling groups of the oligarchic regime. On the other hand, currents with permanent or eventual action in radicalism.

Keywords: Conservatism - Progressivism - Right Lefts 